\title{
AVALIAÇÃO PRELIMINAR DA BIODEGRADAÇÃO DE MICROCISTINA EM LABORATÓRIO PARA O TRATAMENTO AVANÇADO DE ÁGUAS DE ABASTECIMENTO PÚBLICO
}

\author{
Janaína Fagundes Malta - janaina.fmalta@gmail.com \\ Universidade de São Paulo
}

Dra. Eloisa Pozzi Gianotti - elopozzi@sc.usp.br

Universidade de São Paulo

Dr. Davi Gasparini Fernandes Cunha - davig@sc.usp.br

Universidade de São Paulo 


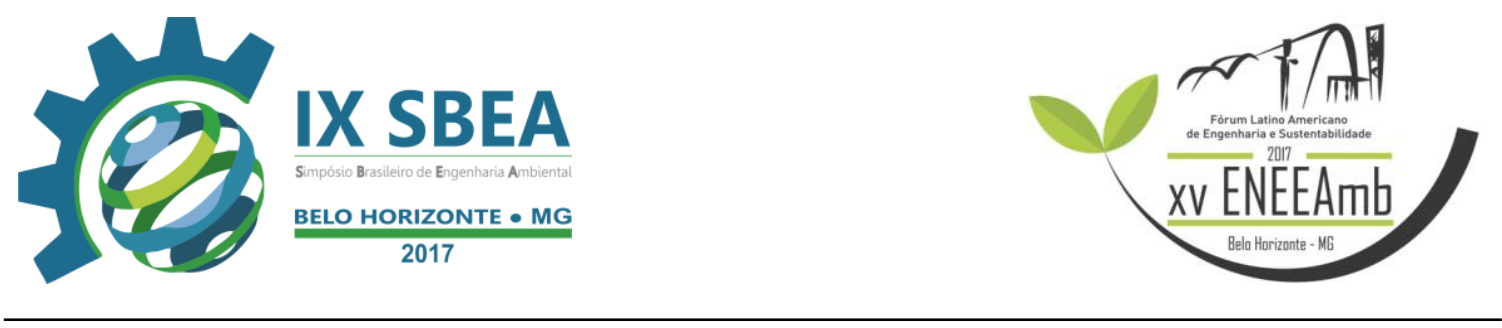

\section{RESUMO}

A microcistina é uma toxina produzida por algumas cianobactérias, como a Microcystis aeruginosa, decorrente de episódios de florações fitoplanctônicas observadas em reservatórios de abastecimento público impactados pelas diversas atividades antropogênicas. Devido a sua toxicidade, a Portaria 2.914 do Ministério da Saúde estabeleceu concentração máxima de $1 \mu \mathrm{g}$. $\mathrm{L}^{-1}$ como padrão de potabilidade. Processos físico-químicos, empregados na maioria das Estações de Tratamento de Água, possuem eficiência limitada na redução da concentração deste poluente, sendo necessário agregar etapas adicionais ao tratamento. A biodegradação tem surgido como uma alternativa para incrementar a eficiência na remoção de contaminantes recalcitrantes e, consequentemente, promover a melhoria na qualidade da água distribuída para os seus diversos usos múltiplos. Nessa pesquisa, foi avaliado o potencial de remoção biológica de microcistina - LR por meio de ensaios utilizando-se como inóculos culturas purificadas de Sphingomonas sp. e Brevundimonas sp. isoladas de amostra de corpo d’água eutrofizado contendo cianobactérias e amostras coletadas na entrada e saída de filtro rápido de uma Estação de Tratamento de Água (ETA), sem adição de inóculos trabalhados em laboratório. Os ensaios sem a adição de inóculos trabalhados em laboratório, com comunidade microbiana autóctone, mostrou as melhores eficiências de remoção de microcistina $(88 \%)$ com concentração remanescente de toxina de, aproximadamente, $1,5 \mu \mathrm{g} . \mathrm{L}^{-1}$, tanto para o crescimento disperso quanto para o aderido da biomassa bacteriana.

Palavras-chave: Cianotoxinas, Degradação biológica, Microcistina, Tratamento avançado de água de abastecimento.

\section{INTRODUÇÃO/OBJETIVO}

Os mananciais de abastecimento público se encontram cada vez mais eutrofizados devido ao aporte de nutrientes, sobretudo fósforo e nitrogênio. Uma das consequências deste impacto é a proliferação de cianobactérias, algumas das quais são conhecidas pela produção de cianotoxinas, como a microcistina - LR, que geram agravos à saúde humana e de animais. A maioria das Estações de Tratamento de Água que utilizam o ciclo completo (etapas de coagulação, floculação, sedimentação ou flotação, filtração e 
desinfecção) possui eficiência limitada na remoção de cianotoxinas, como as microcistinas, cuja concentração máxima de $1 \mu \mathrm{g} . \mathrm{L}^{-1}$ é permitida na água tratada (Portaria MS 2.914/2011).

Microrganismos provenientes de diversas fontes (e.g. sistemas aquáticos naturais, biofilmes formados nas colunas de carvão ativado aplicado no tratamento de água) têm sido caracterizados como potencialmente degradadores de microcistina. Através do mecanismo de degradação/transformação desse contaminante, cepas bacterianas do gênero Sphingomonas, são capazes de reduzir as concentrações da toxina (JONES \& OLUT, 1994; MINILLO et al., 2013; RAMANI et al., 2008; SAITO et al., 2003; SOMDEE et al., 2013). Os resultados encontrados validam a tendência atual de agregar componentes biológicos aos processos físico-químicos convencionais, para melhorar a eficiência de tratamento da água para consumo humano.

O objetivo desta pesquisa foi avaliar o potencial de biodegradação da microcistina, em escala laboratorial e sob diferentes condições de crescimento da biomassa bacteriana e tempo de contato entre os inóculos e o contaminante alvo. Dois tipos de inóculos foram testados para degradar a toxina, com vistas à possível aplicação em águas de abastecimento público até que sejam atingidos as concentrações estabelecidas pelos padrões de potabilidade vigentes no Brasil.

\section{METODOLOGIA}

\subsection{Preparação do extrato de Microcystis aeruginosa}

O extrato de microcistina foi preparado por Ortolan (2016) a partir do cultivo de cepa tóxica de Microcystis aeruginosa (código BB0005), isolada do reservatório de Barra Bonita, São Paulo, Brasil (coordenadas geográficas: 22 31' 15'’S e 48 31' 43' 'W). A linhagem foi depositada na Coleção de Cultura de Microalgas (WDCM85) da Universidade Federal de São Carlos (UFSCar).

Para o cultivo da cianobactéria, utilizou-se meio WC por 30 dias em temperatura de $24 \pm 1^{\circ} \mathrm{C}$, com aeração contínua, intensidade luminosa de $60 \mu \mathrm{E} \cdot \mathrm{m}^{-2} \cdot \mathrm{s}^{-1}$ e fotoperíodo de 12 horas. $\mathrm{d}^{-1}$. Com o intuito de promover a lise celular para a liberação das microcistinas intracelulares no meio, foram realizadas repetições de quatro séries de congelamento/descongelamento das amostras. Em seguida, para a separação do material 


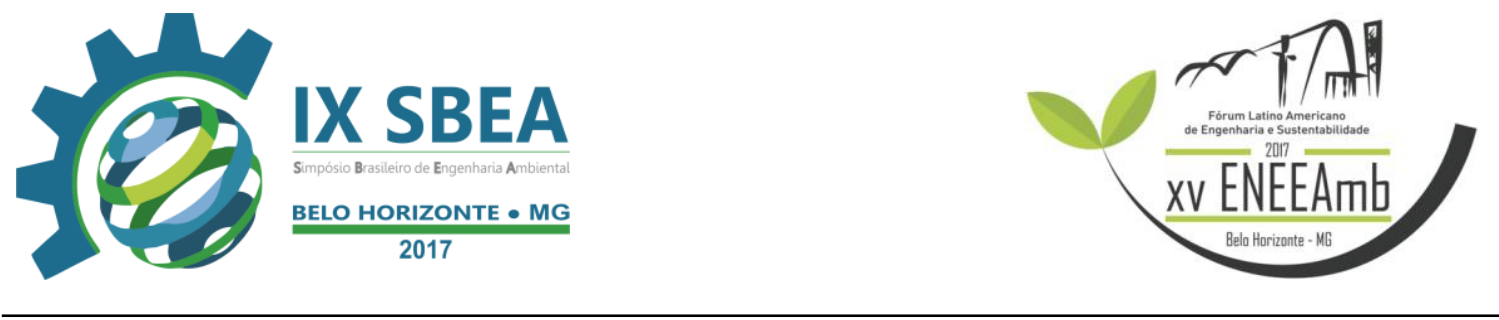

particulado, o extrato contendo as cianotoxinas dissolvidas foi centrifugado por 10 minutos, a $11.000 \mathrm{rpm} \mathrm{e} 4^{\circ} \mathrm{C}$, e armazenado em freezer até a sua utilização no ensaio.

Em teste realizado no Laboratório de Toxinas e Produtos Naturais de Algas do Departamento de Análises Clínicas e Toxicológicas, Faculdade de Ciências Farmacêuticas, Universidade de São Paulo (USP), utilizando a Técnica de detecção LCESI-MS/MS, a variante da cianotoxina encontrada na amostra foi exclusivamente a microcistina-LR (MC-LR) e, por meio do Ensaio do Imunoadsorvente Ligado à Enzima - ELISA, quantificou-se a concentração da cianotoxina no extrato bruto centrifugado, cujo valor aproximado foi de $356 \mu \mathrm{g} . \mathrm{L}^{-1}$.

Para o presente estudo, foi escolhida a concentração inicial da microcistinade $20 \mu \mathrm{g} . \mathrm{L}^{-1}$, por ser frequentemente observada em florações de cianobactérias em reservatórios de abastecimento de água (CHORUS \& BARTRAM, 1999).

\subsection{Microbiota potencialmente degradadora de microcistina}

As colônias isoladas nas maiores diluições $\left(10^{-5}\right.$ e $\left.10^{-6}\right)$ em meio nutriente genérico das amostras de água eutrofizada do reservatório de Barra Bonita (SP) e mantidas em glicerol a $-80^{\circ} \mathrm{C}$, foram caracterizadas como Sphingonomas sp. e Brevundimonas sp..O sequenciamento dos nucleotídeos foi feito em sequenciador ABI 377 DNA Sequencer (Perkin Elmer - USA) na empresa Macrogen (korea).

Os inóculos relativos à comunidade microbiana autóctone foram obtidos na entrada e saída dos filtros da Estação de Tratamento de Água da cidade de São Carlos (SP). Para a retirada do excesso de sólidos mais grosseiros, as amostras foram filtradas em membrana de $0,6 \mu \mathrm{m}$ e, em seguida, centrifugação por 10 minutos, rotação de 11.000rpm, para a formação de pellets. Após estas etapas, os inóculos foram mantidos sob refrigeração a $4^{\circ} \mathrm{C}$ até o dia inicial do experimento.

\subsection{Ensaios de biodegradação de microcistina em escala de bancada}

Os ensaios de biodegradação de microcistina foram feitos em frascos erlenmeyes de $250 \mathrm{~mL}$, para os diferentes tratamentos (Figura 1 e Tabela 1). Foi definido um volume total de $100 \mathrm{~mL}$ de amostra, composto por $10 \% \mathrm{v} / \mathrm{v}$ dos inóculos das culturas purificadas e da microbiota autóctone com concentração inicial de microcistina $\left(20 \mu \mathrm{g} . \mathrm{L}^{-1}\right)$ e meio 
mineral Zinder (ZINDER et al., 1984) acrescido de vitaminas (WIDDEL et al., 1981) e solução traço de metais (ZINDER \& KOCH, 1984). A camada suporte escolhida para a imobilização da biomassa bacteriana foi a espuma de poliuretano com flexibilidade de densidade e tamanho das partículas, elevada porosidade interna e difícil degradação biológica (ZAIAT, 1996). Os ensaios foram realizados a $22 \pm 1^{\circ} \mathrm{C}$ em incubadoras no escuro por um período de 10 dias. Nos dias $0,2,3,4,7$ e 10, foram retiradas alíquotas de $1 \mathrm{~mL}$ para análise da concentração residual de microcistina, realizada pelo método bioquímico de Ensaio do Imunoadsorvente Ligado à Enzima (ELISA).

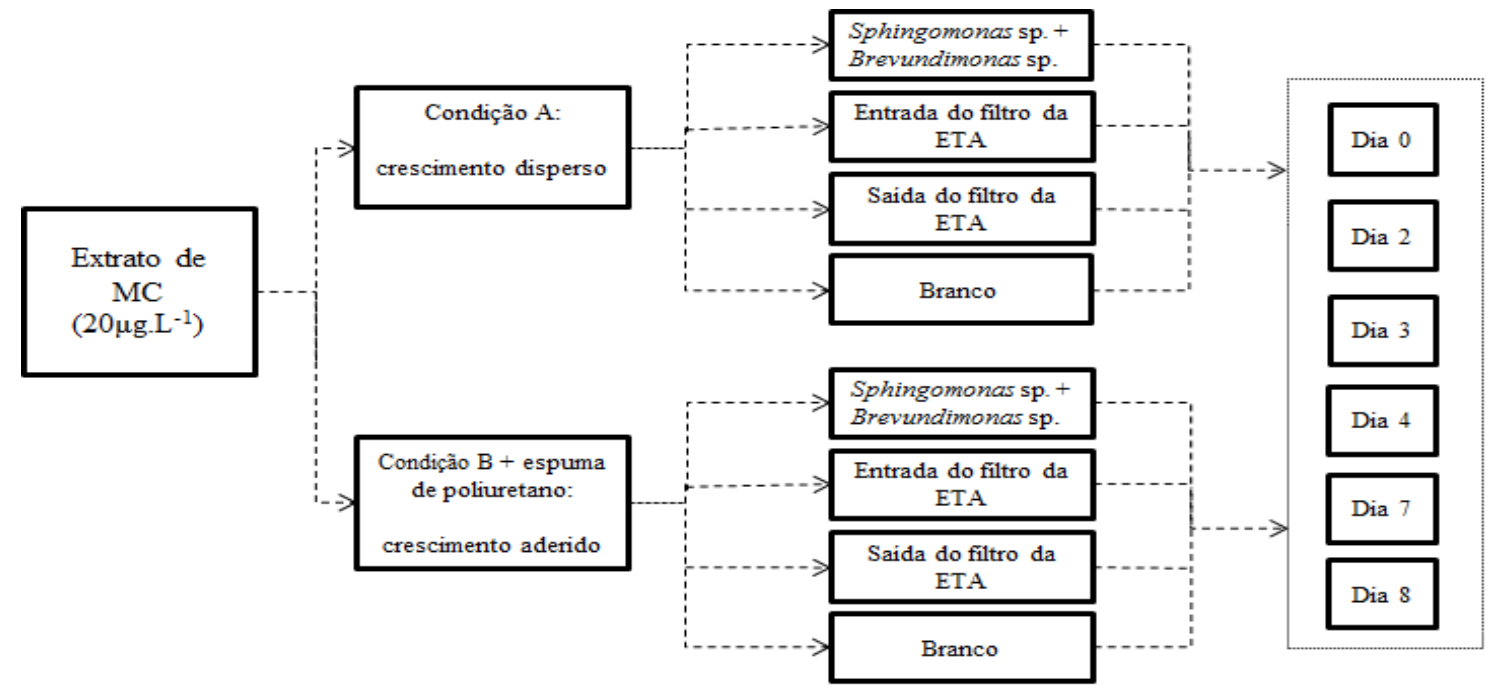

Figura 1 - Fluxograma dos ensaios de biodegradação da microcistina $\left(20 \mu \mathrm{g} . \mathrm{L}^{-1}\right)$ na presença de diferentes inóculos purificados e microbiota autóctone

Fonte: da própria autora (2017). 


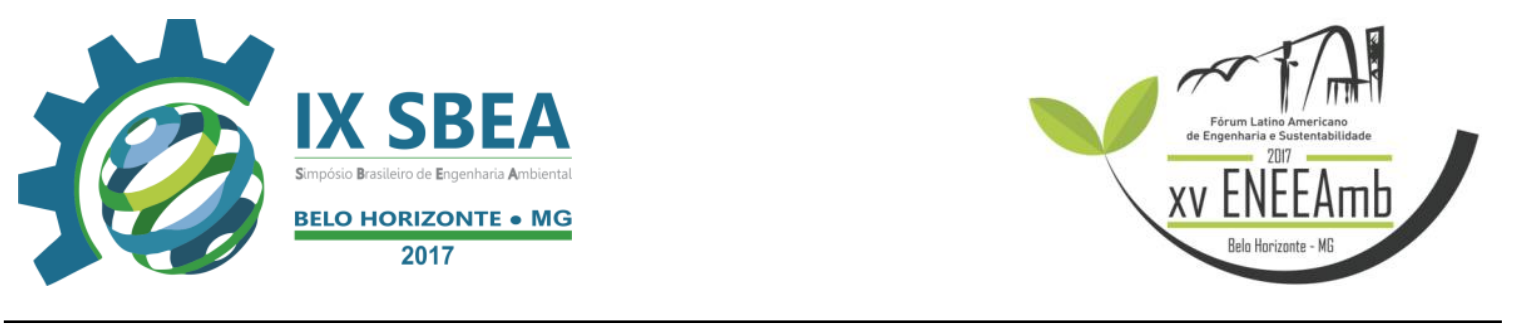

Tabela 1 - Condições experimentais adotadas nos ensaios de biodegradação de microcistina

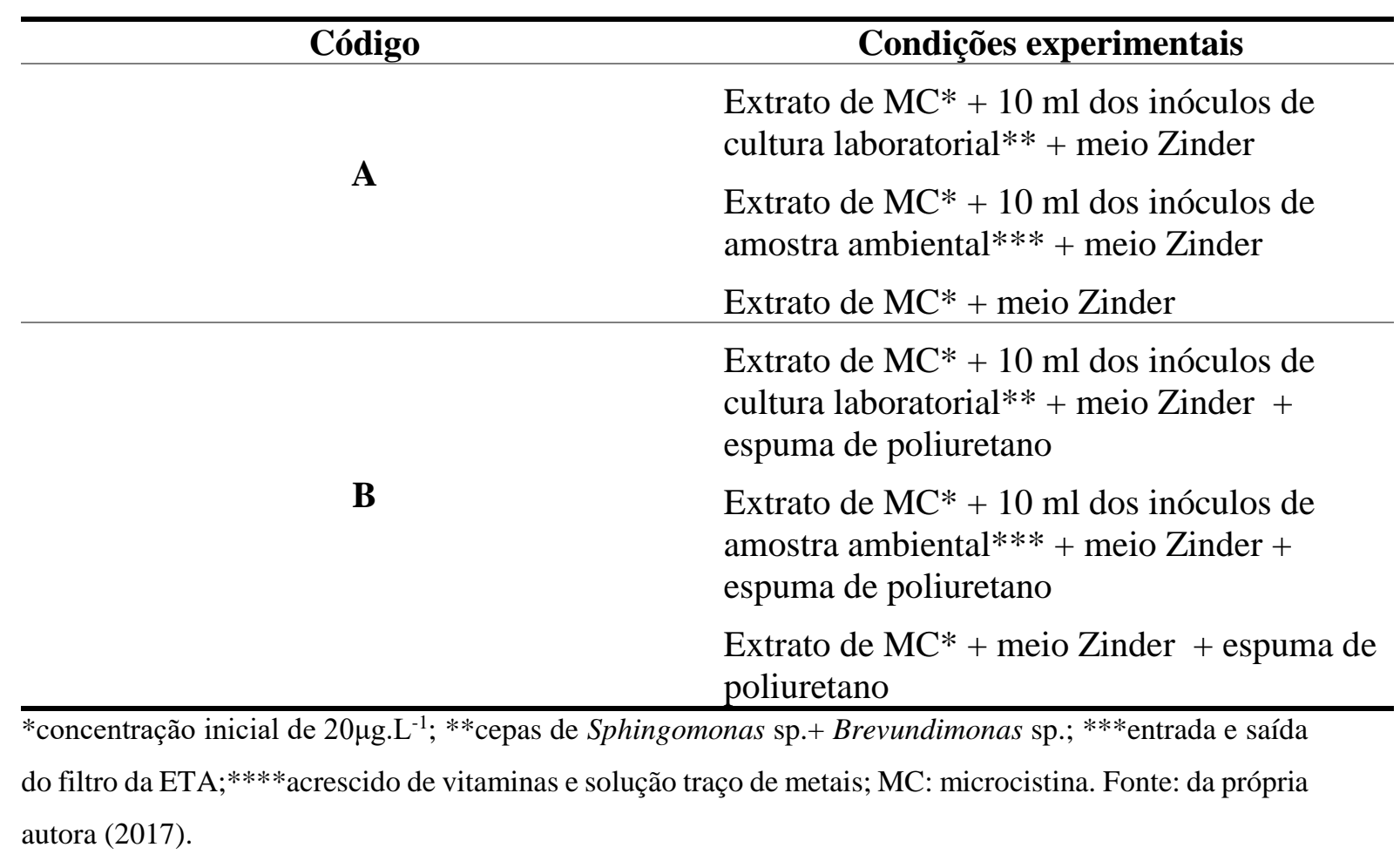

\section{RESULTADOS E DISCUSSÃO}

As Figuras 2 e 3 mostram as concentrações residuais de microcistina nos diferentes tratamentos, obtidas ao longo dos 10 dias de ensaio, para o crescimento disperso e aderido da biomassa bacteriana, respectivamente. Nos primeiros seis dias, a concentração residual de microcistina foi de, aproximadamente, $10 \mu \mathrm{g} . \mathrm{L}^{-1}$, decaindo consideravelmente a sua concentração após o sexto dia e degradada em até $70 \%$ de sua concentração inicial no décimo dia, tanto para a condição experimental A quanto para a condição B.

O tratamento inoculado com as culturas purificadas de Sphingomonas sp. e Brevundimonas sp. obteve uma eficiência de remoção da microcistina $13 \%$ a mais (de 72 para $85 \%$ ) na presença de uma camada suporte para a sua imobilização. Já os tratamentos inoculados com a microbiota autóctone demonstraram melhor desempenho quando dispersas no meio líquido, como mostra a Figura 4. Mesmo comparando-se a eficiência de remoção pela ação dos microrganismos utilizados neste estudo, a presença/ausência 


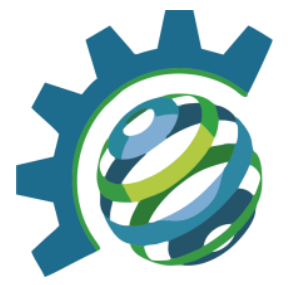

de uma camada suporte apresentou resultados finais próximos (remoção aproximada de $80 \%$ para microbiota autóctone e $70 \%$ para as culturas purificadas). No entanto, ainda são escassas as pesquisas que abordam o potencial dos biofilmes na remoção de microcistina, sendo necessário estudos mais aprofundados.

Alguns microrganismos, quando expostos à microcistina, têm demonstrado capacidade de biodegradá-la, utilizando-a como fonte de carbono e energia para o seu crescimento, metabolismo e reprodução (VALLERO, 2010). O processo de biodegradação da microcistina pode ser distinguido em duas fases: a fase lag (adaptação ou latência da microbiota) e a fase de rápida degradação (SAITOU et al., 2002). Tal comportamento de biodegradação foi observado nesta pesquisa, sendo a fase de rápida degradação observada após o sétimo dia dos experimentos, no qual a concentração residual encontrada esteve abaixo de $10 \mu \mathrm{g} \cdot \mathrm{L}^{-1}$ em todas as amostras e condições analisadas.

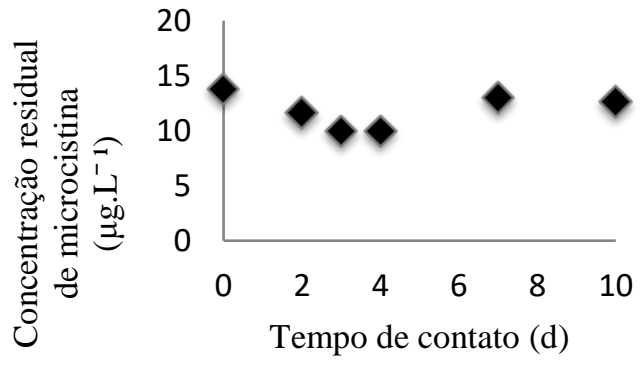

(a)

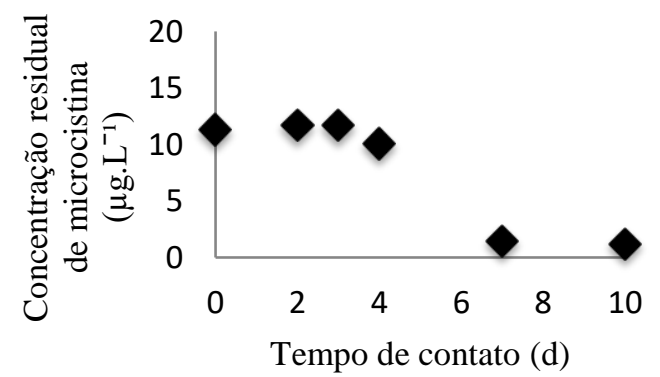

(c)

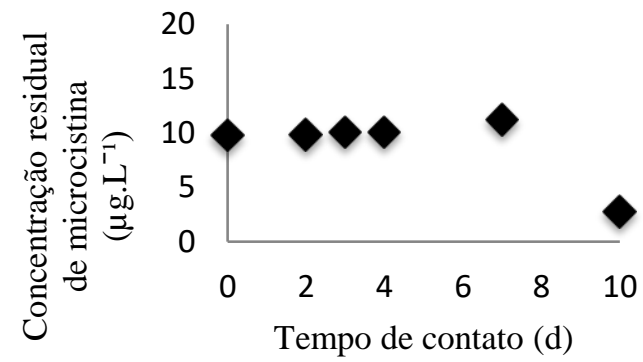

(b)

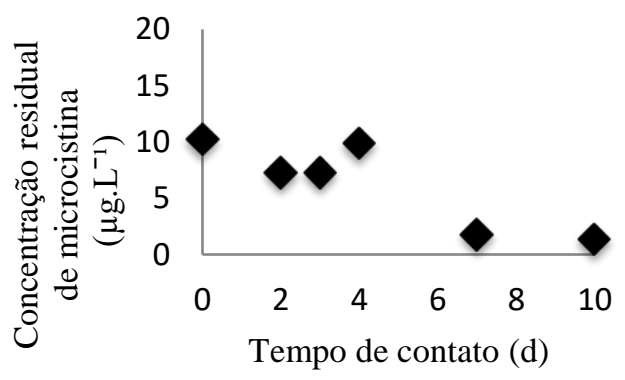

(d)

Figura 2 - Concentração residual de microcistina, na condição A, para os tempos de contato 0, 2, 3,4, 7 e 10 dias: (a) branco; (b) Sphingomonas sp.+ Brevundimonas sp.; (c) entrada do filtro da ETA; (d) saída do filtro da ETA 


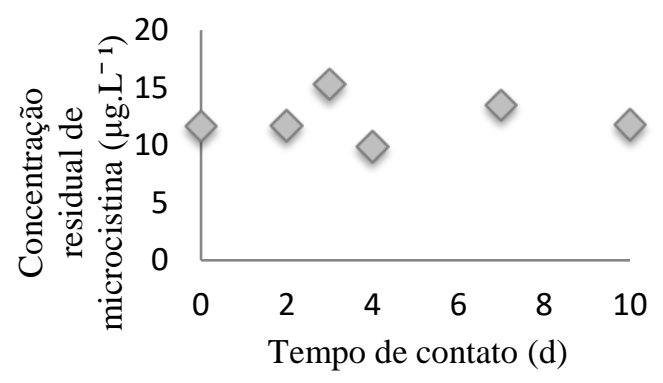

(a)

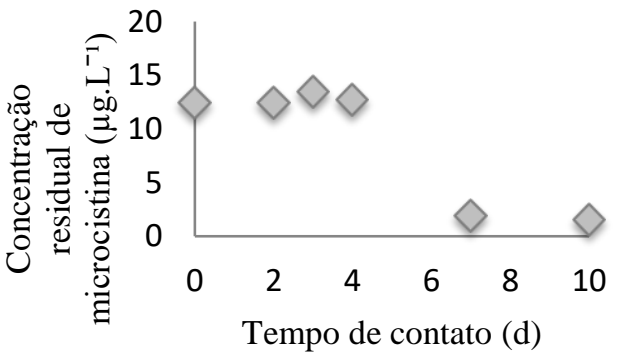

(c)

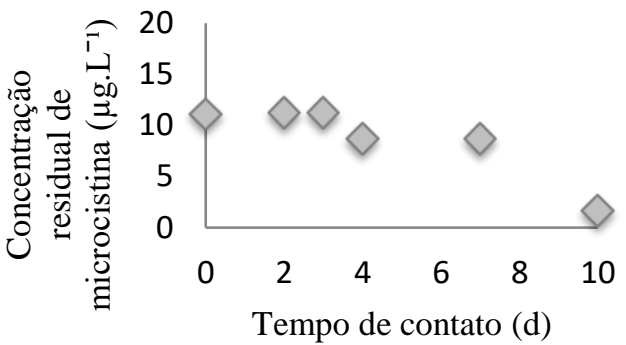

(b)

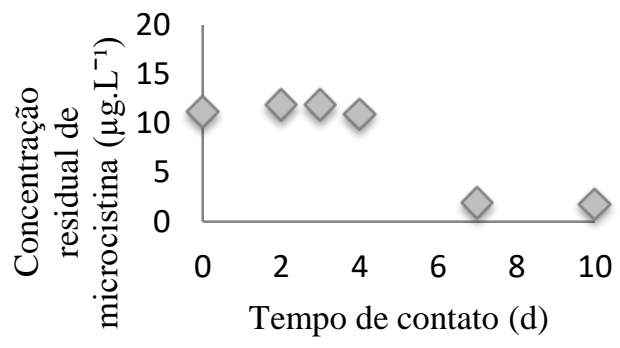

(d)

Figura 3 - Concentração residual de microcistina, na condição B, para os tempos de contato 0, 2, 3,4, 7 e 10 dias (a) branco; (b) Sphingomonas sp.+ Brevundimonas sp.; (c) entrada do filtro da ETA; (d) saída do filtro da ETA

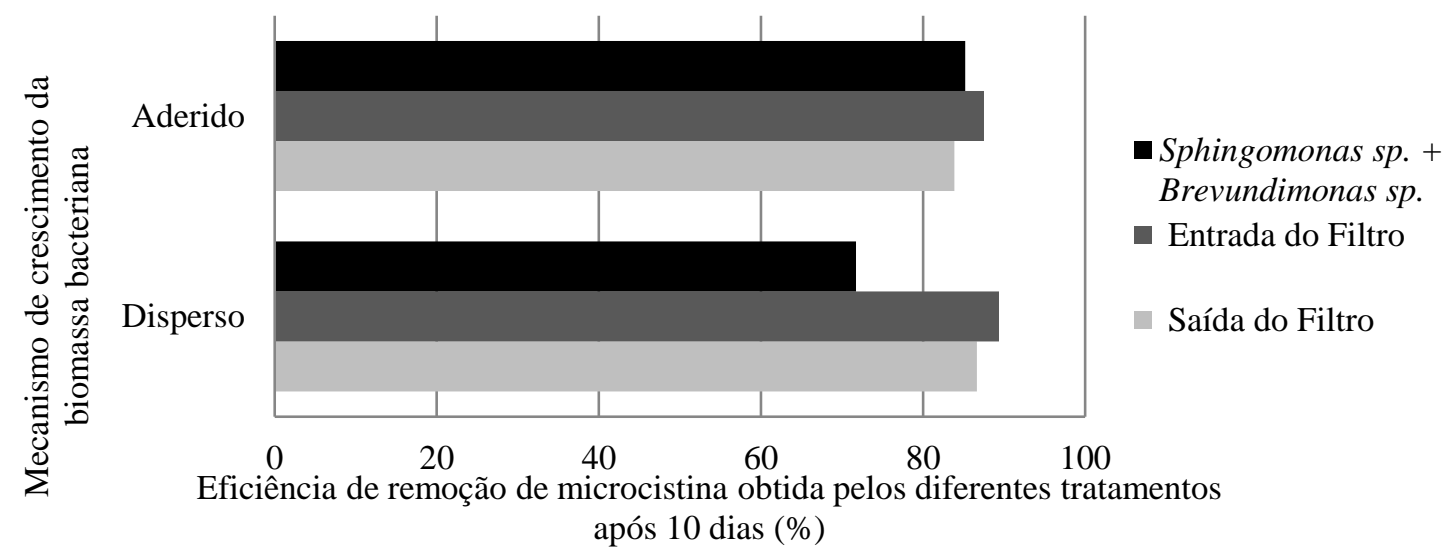

Figura 4 - Comparação entre as eficiências obtidas naremoção da microcistina para a biomassa em crescimento aderido $\mathrm{x}$ a biomassa em crescimento disperso, dos tratamentos contendo Sphingomonas sp. e Brevundimonas sp. e entrada e saída do filtro da ETA após o décimo dia dos ensaios de biodegradação 


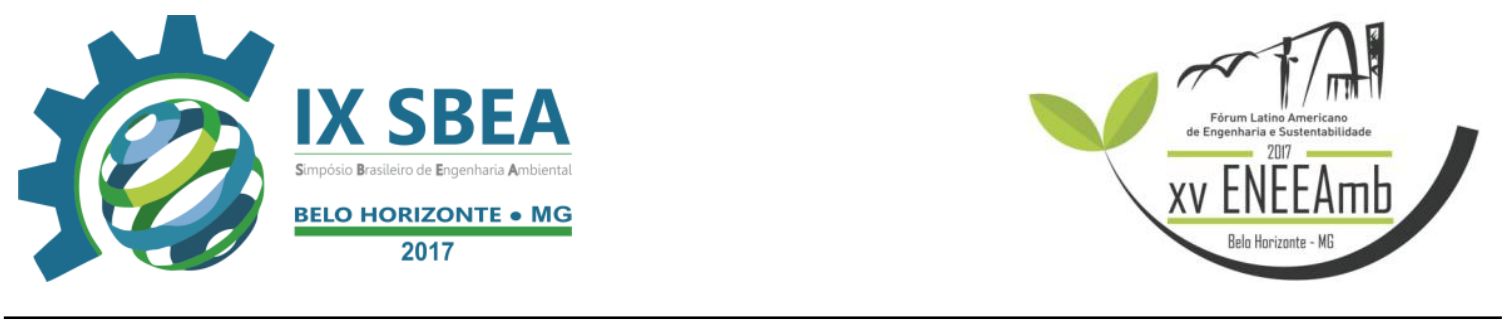

Devido a sua estrutura cíclica da molécula de microcistina mantém uma alta estabilidade química, conferindo a ela propriedades como persistência na água e resistência a altas temperaturas. No estudo conduzido por Cousins et al. (1996), foi comparada a degradação de uma concentração de $10 \mu \mathrm{g} . \mathrm{L}^{-1}$ e tempo de contato de 27 dias entre os inóculos e a microcistina. Os resultados encontrados, para uma concentração residual de microcistina abaixo do limite de detecção, na amostra contendo água de um reservatório de abastecimento esterilizada e não esterilizada foram de 12 e 7 dias, respectivamente, o que demonstra o potencial de microrganismos em aumentar a taxa de degradação da toxina (GAGALA; MANKIEWICZ-BOCZEK, 2012). Em 1994 Jones e Orr conduziram um dos primeiros estudos que identificaram cepas bacterianas capazes de biodegradar a microcistina, pertencentes à família Sphingomonadaceae e que já são reconhecidas por reduzirem a concentração da toxina em águas contaminadas. Além delas, outras cepas de Arthrobacter sp., Brevibacterium sp., Rhodococcus sp., Burkholderia sp., Methylobacillus sp. também são apontadas como microrganismos potencialmente degradadores de microcistina (HU et al., 2009; LAWTON et al., 2011; LEMES et al., 2008)

\section{CONCLUSÕES/RECOMENDAÇÕES}

A fixação da microbiota em meio suporte (espuma de poliuretano) demonstrou as melhores eficiências de remoção após os 10 dias dos ensaios, atingindo valores de aproximadamente 85,88 e $84 \%\left(1,6 \mu \mathrm{g} . \mathrm{L}^{-1}, 1,5 \mu \mathrm{g} . \mathrm{L}^{-1}\right.$ e $\left.1,8 \mu \mathrm{g} . \mathrm{L}^{-1}\right)$, pelos inóculos purificados e da entrada e saída do filtro, respectivamente. Os valores encontrados atingiram valores próximos ao que se é estabelecido pelo padrão de potabilidade vigente no Brasil.

O consórcio microbiano autóctone demonstrou maior capacidade de biodegradar a microcistina, em um menor intervalo de tempo, quando comparado às culturas purificadas. Após o sétimo dia de ensaio, já era possível observar concentrações residuais de microcistina abaixo de $2 \mu \mathrm{g} . \mathrm{L}^{-1}$. Tal comportamento é um fator importante na operação de ETAs, que visam um menor tempo de retenção da água em suas unidades. Entretanto, tornam-se necessários estudos mais detalhados caracterizando a microbiota autóctone e os possíveis fatores que possam otimizar a atividade de tais organismos na degradação da 


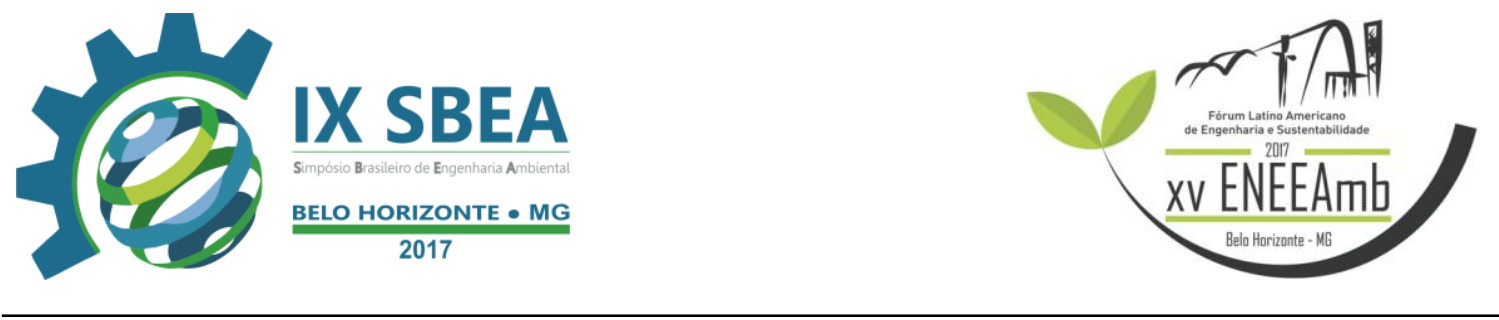

microcistina, tais como temperatura, fotodegradação, concentração de microrganismos, presença/ausência de meio suporte para a formação de um biofilme. Em ensaios futuros tais fatores serão contemplados nesta linha de pesquisa.

\section{REFERÊNCIAS BIBLIOGRÁFICAS}

BRASIL. Ministério da Saúde. Portaria n ${ }^{\circ}$ 2.914, de 12 de dezembro de 2011. Dispõe sobre os procedimentos de controle e de vigilância da qualidade da água para consumo humano e seu padrão de potabilidade. Diário Oficial da República federativa do Brasil, Brasília, 14 dezembro 2011. Seção 1.

CHORUS, INGRID; BARTRAM, J. Toxic Cyanobacteria in Water: A guide to their public health consequence monitoring and management. London: [s.n.]. v. 48

COUSINS, I. T. et al. Biodegradation of microcystin-LR by indigenous mixed bacterial populations. Water Research, v. 30, n. 2, p. 481-485, 1996.

GAGALA, I.; MANKIEWICZ-BOCZEK, J. The Natural Degradation of Microcystins (Cyanobacterial Hepatotoxins) in Fresh Water - the Future of Modern Treatment Systems and Water Quality Improvement. Polish Journal of Environmental Studies, v. 21, n. 5, p. 1125-1139, 2012.

$\mathrm{HU}, \mathrm{L}$. BIN et al. Isolation of a Methylobacillus sp . that degrades microcystin toxins associated with cyanobacteria. New Biotchnology, v. 26, n. October, 2009.

JONES, G. J.; OLUT, P. T. Release and degradation of microcystin following algicide treatment of Microcystis Aeruginosa bloom in a recreational lake, as determined by HPLC and protein phosphatase inhibition assay. Water Research, v. 28, n. 4, p. 871876, 1994.

LAWTON, L. A. et al. Novel bacterial strains for the removal of microcystins from drinking water. Water Science and Technology, v. 63, n. 6, p. 1137-1142, 2011.

LEMES, G. A. F. et al. Biodegradation of microcystins by aquatic Burkholderia sp. from a South Brazilian coastal lagoon. Ecotoxicology and Environmental Safety, v. 69, n. 3, p. 358-365, 2008.

MINILLO, A. et al. Biodegradação da hepatotoxina (D-Leu1) - microcistina-LR por bactérias presentes em filtros biológicos de carvão. Engenharia Sanitaria e Ambiental, v. 18, n. 3, p. 205-214, 2013.

ORTOLAN, A. V. S. Adsorção com carvão ativado granular e degradação biológica para o tratamento avançado de águas de abastecimento: remoção de microcistina em escala laboratorial. p. 94, 2016. 


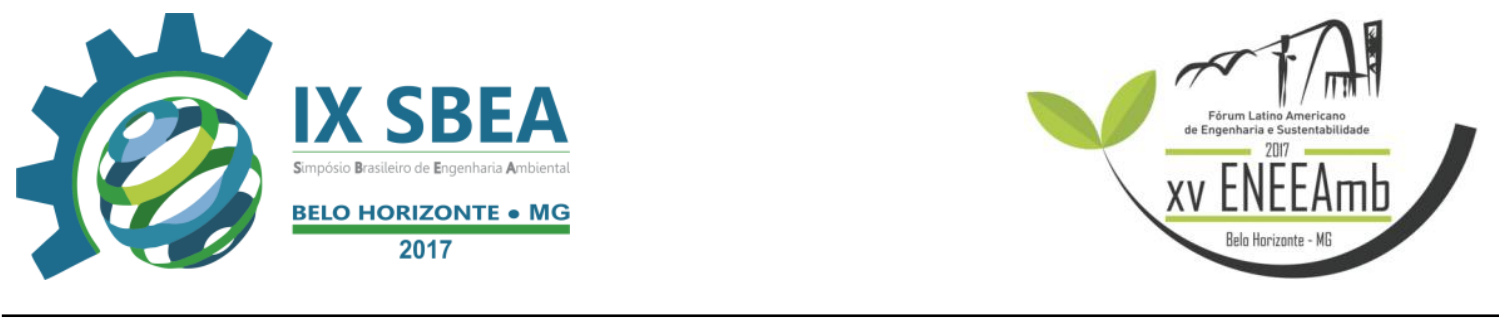

RAMANI, A.; REIN, K., SHETTY, K.G.; JAYACHANDRAN, K. Microbial Degradation of Microcystin in Florida`s Freshwaters. Springer Science, v. 23, n. 1, p. 17, 2008.

SAITO, T. et al. Detection and sequencing of the microcystin LR-degrading gene, mlrA, from new bacteria isolated from Japanese lakes. FEMS Microbiology Letters, v. 229, n. 2, p. 271-276, 2003.

SAITOU, T. et al. Degradation of microcystin by biofilm in practical treatment facility. Water Science and Technology, v. 46, n. 11-12, p. 237-244, 2002.

SOMDEE, T. et al. Degradation of [ Dha 7 ] MC-LR by a Microcystin Degrading Bacterium Isolated from Lake Rotoiti, New Zealand. ISRN Microbiology, v. 2013, p. $1-8,2013$.

VALLERO, D. A. Applied Microbial Ecology: Bioremediation. In: Environmental Biotechnology: A Biosystems Approach. 1. ed. [s.l: s.n.]. p. 750.

WIDDEL, FRIEDRICH; PFENNING, N. Isolation of New Sulfate-Reduzing Bacteria Enriched with Acetate from Saline Environments. Description of Desulfobacter postgatei gen.nov., sp.nov. Archives of Microbiology, n. 129, p. 395-400, 1981.

ZAIAT, M.; CABRAL, A.K.A.; FORESTI, E. Reator Anaeróbio Horizontal de Leito Fixo Para Tratamento de Águas Residuárias: Concepção e Avaliação Preliminar de Desempenho. Revista Brasileira de Engenharia - Caderno de Engenharia Química, v. 11, n. 2, p. 33-42, 1994.

ZINDER, S. H. et al. Methanogenesis in a Thermophilic ( $58^{\circ} \mathrm{C}$ ) Anaerobic Digestor : Methanothrix sp . as an Important Aceticlastic Methanogen. Applied and Environmental Microbiology, v. 47, n. 4, p. 796-807, 1984.

ZINDER, S. H.; KOCH, M. Non-aceticlastic methanogenesis from acetate: acetate oxidation by a thermophilic syntrophic coculture. Archives of Microbiology, n. 138, p. 263-272, 1984. 